\title{
Carrier control in polycrystalline ZnO:Ga thin films via nitrogen implantation
}

K. S. Shtereva ${ }^{\mathrm{a}, b^{*}}$, I. Novotny ${ }^{\mathrm{a}}$, R. V. Tvarozek ${ }^{\mathrm{a}}$, M. Vojs ${ }^{\mathrm{a}}$, S. Flickyngerova ${ }^{\mathrm{a}}$, P. Sutta ${ }^{\mathrm{c}}$,

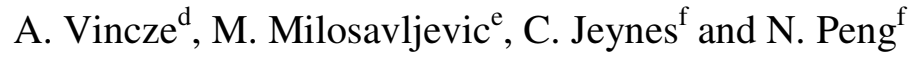

a) Institute of Electronics and Photonics, Slovak University of Technology, Ilkovičova 3, 81219 Bratislava, Slovakia

b) Department of Electronics, University of Rousse, Studentska 8, 7017 Rousse, Bulgaria

c) West Bohemia University, New technologies - Research Center, Univerzitni 8, 30614 Plzen, Czech Republic

d) International Laser Centre, Bratislava, Ilkovicova 3, 81219 Bratislava, Slovakia

e) VINCA Institute of Nuclear Sciences, University of Belgrade, P. O. Box 522, Belgrade 11001, Serbia

f) University of Surrey, Ion Beam Centre, Guildford GU2 7XH, England

*Corresponding author: KShtereva@ecs.ru.acad.bg

Published as :- K. S. Shtereva, I. Novotny, V. Tvarozek, M. Vojs, S. Flickyngerova, P. Sutta, A. Vincze, M. Milosavljevic, C. Jeynes, and N. Peng, Carrier Control in Polycrystalline ZnO:Ga Thin Films via Nitrogen Implantation, ECS Journal of Solid State Science and Technology, 1 (2012) P237-P240; http://dx.doi.org/10.1149/2.003206jss 


\begin{abstract}
The electrical characteristics of gallium-doped zinc oxide ( $\mathrm{ZnO}: \mathrm{Ga})$ thin films prepared by rf diode sputtering were altered via nitrogen implantation by performing two implants at $40 \mathrm{keV}$ and $80 \mathrm{keV}$ with doses of $1 \times 10^{15}$ and $1 \times 10^{16} \mathrm{~cm}^{-2}$ to achieve a $p$-type semiconductor. An implantation of $1 \times 10^{15} \mathrm{~cm}^{-2} \mathrm{~N}^{+}$-ions yielded a $p$-type with hole concentrations $10^{17}-10^{18} \mathrm{~cm}^{-3}$ in some as-implanted samples. The films annealed at temperatures above $200{ }^{\circ} \mathrm{C}$ in $\mathrm{O}_{2}$ and above $400{ }^{\circ} \mathrm{C}$ in $\mathrm{N}_{2}$ were $n$-type with electron concentrations $10^{17}-10^{20} \mathrm{~cm}^{-3}$. The higher nitrogen concentration (confirmed by SRIM and SIMS), in the films implanted with a $1 \times 10^{16} \mathrm{~cm}^{-2}$ dose, resulted in lower electron concentrations, respectively, higher resistivity, due to compensation of donors by nitrogen acceptors. The electron concentrations ratio $n_{\left(1 \times 10^{15}\right)} / n_{\left(1 \times 10^{16}\right)}$ decreases with increasing annealing temperature. Hall measurements showed that $1 \times 10^{16} \mathrm{~cm}^{-2} \mathrm{~N}$-implanted films became $p$-type after low temperature annealing in $\mathrm{O}_{2}$ at $200{ }^{\circ} \mathrm{C}$ and in $\mathrm{N}_{2}$ at $400{ }^{\circ} \mathrm{C}$ with hole concentrations of $3.2 \times 10^{17} \mathrm{~cm}^{-3}$ and $1.6 \times 10^{19} \mathrm{~cm}^{-3}$, respectively. Nitrogen-implanted $\mathrm{ZnO}: \mathrm{Ga}$ films showed a $c$-axes preferred orientation of the crystallites. Annealing is shown to increase the average transmittance $(>80 \%)$ of the films and to cause band gap widening $(3.19 \div 3.3 \mathrm{eV})$
\end{abstract}

\title{
Keywords:
}

$\mathrm{RF}$ diode sputtering, $\mathrm{ZnO}$ thin films, doping, implantation, carrier concentration crystallographic structure, SIMS, transmittance 


\section{Introduction}

Zinc oxide $(\mathrm{ZnO})$ is a versatile material, which has application in many areas including the vast electronics sector. A $\mathrm{ZnO}$ semiconductor, exhibiting special optical properties (a direct band gap of $3.37 \mathrm{eV}$ and a large exciton binding energy of $60 \mathrm{meV}$ ) has a potential to be employed in the fabrication of photonic devices such as blue and ultraviolet (UV) emitters [1], transparent thin film transistors (TTFT) [2], and photovoltaic devices (PV). At the present time, the transparent conducting $\mathrm{ZnO}$ thin films are used as an electrode material for amorphous silicon (a-Si) and $\mathrm{Cu}(\mathrm{In}, \mathrm{Ga}) \mathrm{Se}_{2}$ (CIGS) solar cells, and have been investigated for electrodes for organic photovoltaic (PV) and organic lightemitting diodes (OLEDs) $[3,4]$. Undoubtedly, the major obstacle to $\mathrm{ZnO}$ exploitation in the fabrication of devices is the difficulty in $p$-type doping. Ion implantation is an important technique for controllable doping in semiconductors, which offers a precise control of the doping levels, doping uniformity and extreme purity of the dopant, as well as low temperature processing. Moreover, ion implantation enables the introduction of dopants that are not soluble or diffusible, and hence, may provide a solution for the p-type limitation in $\mathrm{ZnO}$. The implantation of nitrogen ions into $\mathrm{ZnO}$ can be a promising approach to achieve a $p$-type material. More recent studies on the defects in nitrogen-implanted and annealed $\mathrm{ZnO}$ thin films found two energy levels at approximately $60 \mathrm{meV}$ and $100 \mathrm{meV}$ above the valence band that can play an important role for $p$-type doping [5].

On the basis of the reports for obtaining of $p$-type $\mathrm{ZnO}$ via nitrogen implantation [6,7] and realization of ZnO-based metal-insulator-semiconductor diodes by ion implantation [8], as well as our previous research on $\mathrm{N}$-doped and (Al, Ga):N co-doped 
$\mathrm{ZnO}$ thin films $[9,10]$, we attempted acceptor doping in polycrystalline $\mathrm{ZnO}: \mathrm{Ga}$ thin films by nitrogen implantation.

This work derives from our previous study on $\mathrm{N}$-implanted $\mathrm{ZnO}: \mathrm{Ga}$ thin films (energy $180 \mathrm{keV}$, doses ranging from $1 \times 10^{15} \mathrm{~cm}^{-2}$ to $2 \times 10^{16} \mathrm{~cm}^{-2}$ ), annealed in an $\mathrm{O}_{2}$ or $\mathrm{N}_{2}$ ambient up to $550^{\circ} \mathrm{C}$ [11]. It was found that low implant doses (up to $1 \times 10^{16} \mathrm{~cm}^{-2}$ ) and annealing temperatures up to $400^{\circ} \mathrm{C}$ are more favorable for $p$-type doping. Hall measurements showed a hole concentration of $2.8 \times 10^{19} \mathrm{~cm}^{-3}$, mobility of $0.6 \mathrm{~cm}^{2} / \mathrm{Vs}$, and resistivity of $0.46 \Omega \mathrm{cm}$ in samples implanted with a $1 \times 10^{16} \mathrm{~cm}^{-2}$ dose after annealing in $\mathrm{N}_{2}$ at $400^{\circ} \mathrm{C}$ for $10 \mathrm{~s}$.

In this paper, we report on the changes in electrical, structural and optical properties of double energy (40 keV and $80 \mathrm{keV}$ ) implanted $\mathrm{ZnO}: \mathrm{Ga}$ thin films, deposited on glass and sapphire substrates, annealed up to $800^{\circ} \mathrm{C}$ under $\mathrm{O}_{2}$ and $\mathrm{N}_{2}$.

\section{Experimental Methods}

The $\mathrm{ZnO}: \mathrm{Ga}$ thin films were deposited on Corning 7059 glass substrates and sapphire substrates by rf diode sputtering from a ceramic $\mathrm{ZnO}: \mathrm{Ga}_{2} \mathrm{O}_{3}$ (98wt $\left.\%: 2 \mathrm{wt} \%\right)$ target, a mixture of $\mathrm{ZnO}$ (99.99\% purity) and $\mathrm{Ga}_{2} \mathrm{O}_{3}$ (99.99\% purity). The sputtering was carried out at $1.3 \mathrm{~Pa}$ working pressure in $\mathrm{Ar}(99.999 \%$ purity) atmosphere with an rf power of $600 \mathrm{~W}$. The film thickness of $~ 200 \mathrm{~nm}$ was determined by Dektak 150 instrument.

Ion implantations were done using the Danfysik1090 ion implanter at the Surrey Ion Beam Centre (UK). Singly charged ${ }^{14} \mathrm{~N}^{1+}$ ions were implanted at normal incidence to the target, the ion current was maintained below $1 \mu \mathrm{A} / \mathrm{cm}^{2}$, to avoid beam-heating of the 
samples. In order to obtain almost uniformly doped thin films, a double energy implant was performed, one at $40 \mathrm{keV}$ and the other at $80 \mathrm{keV}$, with doses of $1 \times 10^{15}$ and $1 \times 10^{16} \mathrm{~cm}^{-2}$. The projected ion range and struggle $\left(R_{\mathrm{p}} \pm \Delta R_{\mathrm{p}}\right)$ and total displacements per atom (dpa) were calculated by the SRIM code, using full cascade collisions [12]. The resulting nitrogen profile is almost homogeneous in depth as pictured in figure 1. The calculated ion range and straggle are: $R_{\mathrm{p}}=67 \mathrm{~nm}, \Delta R_{\mathrm{p}}=30 \mathrm{~nm}$ for $40 \mathrm{keV} \mathrm{N}$, and $R_{\mathrm{p}}=121 \mathrm{~nm}, \Delta R_{\mathrm{p}}=45$ $\mathrm{nm}$ for $80 \mathrm{keV} \mathrm{N}$. To activate the implanted ions and repair the damaged area, the implanted films were annealed under $\mathrm{O}_{2}$ and $\mathrm{N}_{2}$ ambient at temperatures varying from 200 to $800^{\circ} \mathrm{C}$.

The electrical parameters of the films were measured from a Hall-effect system with a magnetic field of $0.15 \mathrm{~T}$ at a room temperature (RT). The structure and preferred orientation of the crystallites were evaluated by X-ray diffraction (XRD) on X'pert Pro powder diffractometer (symmetric $\vartheta \vartheta$ geometry), equipped with an ultra-fast linear semiconductor detector PIXcel, using $\mathrm{CuK} \alpha$ radiation $(\lambda=0.154 \mathrm{~nm})$. Secondary Ion Mass Spectrometry (SIMS) depth profiles of the various ionic species were acquired with a TOFSIMS IV analyzer (ION TOF GmbH, Muenster), using a $\mathrm{Cs}^{+}$primary ion beam with energy of $2 \mathrm{keV}$. The distribution of the complex ${ }^{30} \mathrm{NO}^{-}$ions in the film, obtained from SIMS, is uniform (Figure 2) and corresponds rather well to the profile calculated using SRIM. Optical spectrophotometry measurements were carried out from the UV region to the near IR region by an Ava Spec-2048 Fiber Optic Spectrometer. 


\section{Results and Discussions}

Prior to annealing, the electrical parameters (resistivity, a carrier concentration, Hall mobility), microstructure and optical properties of the as-implanted films were investigated in order to evaluate the effects of the $\mathrm{N}$ implantation on their properties. Hall-effect measurements showed that the majority of the films were $n$-type. Depending on the implant dose, the electron concentrations were of order $10^{18}-10^{19} \mathrm{~cm}^{-3}$. However, some films, mainly those implanted with a lower dose of $1 \times 10^{15} \mathrm{~cm}^{-2} \mathrm{~N}^{+}$-ions, were $p$-type with the hole concentrations $10^{17}-10^{18} \mathrm{~cm}^{-3}$.

After performing a post implant annealing, the $\mathrm{N}$-implanted $\mathrm{ZnO}: \mathrm{Ga}$ thin films annealed at temperatures above $200{ }^{\circ} \mathrm{C}$ in $\mathrm{O}_{2}$ and above $400{ }^{\circ} \mathrm{C}$ in $\mathrm{N}_{2}$ became $n$-type. Similar results have been reported from other groups [13]. Figure 3 compares resistivities of the $1 \times 10^{15} \mathrm{~cm}^{-2}$ and $1 \times 10^{16} \mathrm{~cm}^{-2} \mathrm{~N}^{+}$-ions implanted films deposited on sapphire substrates. In figure 4 are plotted the carrier concentrations and mobilities of these films as a function of the annealing temperature. For temperatures between $500 \div 700{ }^{\circ} \mathrm{C}$ there is a falloff in resistivity with increasing temperature, which resulted from the increase of both, the carrier concentration and mobility. The films implanted with a dose of $1 \times 10^{15} \mathrm{~cm}^{-2}$ exhibits higher electron concentrations than those implanted with a $1 \times 10^{16} \mathrm{~cm}^{-2}$ dose at temperatures between $500 \div 700{ }^{\circ} \mathrm{C}$. It is clearly visualized in figure 5 , which presents the ratio of the electron concentration $\left(n_{\left(1 \times 10^{15}\right)} / n_{\left(1 \times 10^{16}\right)}\right)$ for low to high implantation dose versus the annealing temperature in the films annealed in $\mathrm{N}_{2}$ or $\mathrm{O}_{2}$ (an inset) for $10 \mathrm{~s}$. This result is consistent with the SRIM calculations (Figure 1) and the SIMS results (Figure 2), which show higher nitrogen concentrations in the films implanted with $1 \times 10^{16} \mathrm{~cm}^{-2}$. Hence, the 
probability that a nitrogen atom will make a replacement collision with oxygen lattice atom, creating a nitrogen acceptor $\left(\mathrm{N}_{\mathrm{O}}\right)$, increases. Due to the higher donors' compensation, the electrons concentration is reduced and resistivity is increased. Nevertheless, the resulting material remained $n$-type, because the amount of the created acceptor was not sufficient to compensate native and impurity donor defects in the films. When speculating on the possible reasons for $n$-type $\mathrm{N}$-implanted $\mathrm{ZnO}: \mathrm{Ga}$ films one should take into consideration many complex processes that govern the conduction type in $\mathrm{ZnO}$. Calculations based on the first-principles pseudo potential method within the local-density functional approximation (LDA) showed that the type of the donors, which compensate nitrogen acceptors, depends on the nitrogen doping level [14]. At low nitrogen doping levels, nitrogen acceptors are compensated mostly by oxygen vacancies, whereas at high doping levels, the major compensating donors are nitrogen composed donors such as nitrogen molecules and donor defect complexes. Experimental studies on five energies nitrogen-implanted and annealed $\mathrm{ZnO}$ thin films revealed the formation of a deep level approximately $580 \mathrm{meV}$ below the conduction band edge which was ascribed to nitrogen [5]. The concentration of donors in these films was at least one order of magnitude larger than in the as-grown samples. However, $p$-type was measured in films deposited on glass substrates, implanted with $1 \times 10^{16} \mathrm{~cm}^{-2}$ after annealing in $\mathrm{O}_{2}$ at $200^{\circ} \mathrm{C}$ for $10 \mathrm{~s}$ (a hole concentration of $3.2 \times 10^{17} \mathrm{~cm}^{-3}$, mobility of $1 \mathrm{~cm}^{2} / \mathrm{Vs}$, resistivity of $20 \Omega \mathrm{cm}$ ), as well as in films annealed in $\mathrm{N}_{2}$ at $400{ }^{\circ} \mathrm{C}$ for $10 \mathrm{~s}$ (a hole concentration of $1.6 \times 10^{19} \mathrm{~cm}^{-3}$, mobility of $0.8 \mathrm{~cm}^{2} / \mathrm{Vs}$, resistivity of $0.48 \Omega \mathrm{cm})$. Figure 6 illustrate how resistivity, electron concentration and mobility vary with annealing temperature for $1 \times 10^{16} \mathrm{~cm}^{-2} \mathrm{~N}$-implanted $\mathrm{ZnO}$ :Ga films, deposited on glass substrates and annealed in $\mathrm{O}_{2}$ for $10 \mathrm{~s}$. 
Larger impurity concentrations of both, donors and acceptors, result in low mobility $0.4-3.8 \mathrm{~cm}^{2} / \mathrm{V}$ in the films deposited on sapphire substrates (Figure 4), and $0.1-0.6 \mathrm{~cm}^{2} / \mathrm{Vs}$ in the films deposited on glass substrates (Figure 6). It is known from theory that the carrier mobility depends on the scattering events that take place inside the semiconductor. In case of polycrystalline and other high defect materials, ionized impurity scattering and scattering by neutral impurity atoms and defects tend to dominate. Elevating the annealing temperature can activate some of the impurity gallium atoms to move from interstitial to $\mathrm{Zn}$ sites, making them effective donors, and/or some of the interstitial impurity nitrogen atoms to substitute for an $\mathrm{O}$ atom, thus, becoming acceptors. Hence, the increase in mobility with increasing annealing temperature resulted from the improvement of the crystalline structure as confirmed from X-ray diffraction measurements.

In figure 7 are plotted XRD patterns obtained from the as-implanted samples for two doses. The dominant (002) diffraction line indicates that they are polycrystalline with a $c$ axes preferred orientation. The XRD patterns reveal that the studied $\mathrm{ZnO}$ :Ga films are not amorphized upon ion implantation which confirms other authors observation that many ceramic metal-oxide or metal-nitride thin film nanocomposites are resistant to amorphization upon high dose ion irradiation [15]. However, the implanted doses were sufficiently high (up to 5.7-8.9 $\mathrm{dpa}$ ) to induce a rearrangement of the crystalline structure, as shown by XRD analysis. The variation of the parameters of the diffraction lines (their position, Full Width at Half Maximum (FWHM), and relative intensity), reflects doping effects on the processes, controlling the film texture. The diffraction lines peak position shifts towards the smaller $2 \vartheta$ diffraction angles for the as-implanted samples. According to 
the Bragg Law, this shift denotes that the lattice constant increases. The interstitial defects (nitrogen and gallium impurity atoms), cause increase in the interplanar spacing $(d)$ and lattice expansion. The integrated intensity of the (002) diffraction line increases with increasing dose suggesting an improvement of the crystalline structure presumably, due to a reduction in the vacancy defects when nitrogen substituted for oxygen. The post-implant annealing reduces the structure damage, hence, the integrated intensity of a (002) diffraction line increases with increasing anneal temperature, suggesting more textured structure of the film (Figure 8). The sample denoted by $a$ is not annealed. Three steps annealing in $\mathrm{N}_{2}$ at different temperatures and times were performed on samples $b$ and $c$ as described: $\quad$ sample $\quad b \quad 10 \mathrm{~s} / 400^{\circ} \mathrm{C}+10 \mathrm{~s} / 400^{\circ} \mathrm{C}+10 \mathrm{~s} / 400^{\circ} \mathrm{C} ; \quad$ sample $\quad c$ $10 \mathrm{~s} / 400^{\circ} \mathrm{C}+10 \mathrm{~s} / 600^{\circ} \mathrm{C}+30 \mathrm{~min} / 600^{\circ} \mathrm{C}$. Annealing activate some interstitial atoms to move from an interstitial site to zinc or oxygen lattice sites, which will cause the reduction of the interplanar spacing. A shift towards higher $2 \vartheta$ diffraction angles reflects this rearrangement of atoms and the corresponding lattice chances.

The $\mathrm{N}$-implanted $\mathrm{ZnO}: \mathrm{Ga}$ thin films are highly transparent with an average transmittance $>80 \%$ in the wavelength range of $390-1100 \mathrm{~nm}$. The transmittance data were acquired over the wavelength range of $200<\lambda<1100 \mathrm{~nm}$. In figure 9 are compared optical transmittance spectra (including glass substrate) of the as-implanted and $\mathrm{N}$ implanted ZnO:Ga samples, annealed under $\mathrm{N}_{2}$ or $\mathrm{O}_{2}$ atmosphere for $10 \mathrm{~s}$ at $600^{\circ} \mathrm{C}$. The average transmittance increases with increasing annealing temperature (Figure 9 inset) due to the reduction of the structural defects. 
The transmittance data were used to calculate the direct transition optical absorption coefficients $(\alpha)$. Figure 10 presents dependence of $(\alpha h v)^{2}$ on photon energy of one energy for $\mathrm{N}$-implanted $\mathrm{ZnO}: \mathrm{Ga}$ films, not annealed and annealed in $\mathrm{N}_{2}$ or $\mathrm{O}_{2}$ atmosphere for $10 \mathrm{~s}$ at $600^{\circ} \mathrm{C}$. The optical band gap $\left(E_{\mathrm{g}}\right)$ was determined by extrapolating the linear part of each curve. The bandgap varies from $\sim 3.19 \mathrm{eV}$ for the as-implanted films to $\sim 3.3 \mathrm{eV}$ for the $\mathrm{N}$ implanted and annealed $\mathrm{ZnO}: \mathrm{Ga}$ films.

\section{Conclusion}

ZnO:Ga films were deposited on Corning 7059 glass substrates and sapphire substrates by rf diode sputtering. In order to obtain an uniform nitrogen distribution in the film depth, two energies implantations, one at $40 \mathrm{keV}$ and the other at $80 \mathrm{keV}$, with doses of $1 \times 10^{15} \mathrm{~cm}^{-2}$ and $1 \times 10^{16} \mathrm{~cm}^{-2}$, were carried out following by post-implant annealing in $\mathrm{N}_{2}$ and $\mathrm{O}_{2}$ at temperatures up to $800^{\circ} \mathrm{C}$. The $\mathrm{N}$-implanted $\mathrm{ZnO}: \mathrm{Ga}$ thin films annealed at temperatures above $200{ }^{\circ} \mathrm{C}$ in $\mathrm{O}_{2}$ and above $400{ }^{\circ} \mathrm{C}$ in $\mathrm{N}_{2}$ were $n$-type with electron concentrations $10^{17}-10^{20} \mathrm{~cm}^{-3}$. Due to the higher compensation of the donors by nitrogen acceptors, the electron concentration is reduced and resistivity is increased in $1 \times 10^{16} \mathrm{~cm}^{-2}$ $\mathrm{N}$-implanted films compared to those implanted with a $1 \times 10^{15} \mathrm{~cm}^{-2}$ dose. The ratio of the electron concentration $\left.\left(n_{\left(1 \times 10^{15}\right)}\right) / n_{\left(1 \times 10^{16}\right)}\right)$ decreases with increasing annealing temperature. Hall measurements showed a $p$-type in films implanted with $1 \times 10^{16} \mathrm{~cm}^{-2}$ after annealing in $\mathrm{O}_{2}$ at $200{ }^{\circ} \mathrm{C}$ (a hole concentration of $3.2 \times 10^{17} \mathrm{~cm}^{-3}$, mobility of $1 \mathrm{~cm}^{2} / \mathrm{Vs}$, resistivity of $20 \Omega \mathrm{cm}$, and), and in $\mathrm{N}_{2}$ at $400{ }^{\circ} \mathrm{C}$ with (a hole concentration of $1.6 \times 10^{19} \mathrm{~cm}^{-3}$, mobility of 
$0.8 \mathrm{~cm}^{2} / \mathrm{Vs}$, resistivity of $\left.0.48 \Omega \mathrm{cm}\right)$. Larger impurity concentrations of both types, donors and acceptors, result in low mobility $0.4-3.8 \mathrm{~cm}^{2} / \mathrm{V}$ in the films deposited on sapphire substrates, and $0.1-0.6 \mathrm{~cm}^{2} / \mathrm{Vs}$ in the films deposited on glass substrates. XRD patterns reveals that the $\mathrm{ZnO}: \mathrm{Ga}$ films are not amorphized upon ion implantation. The as-implanted and annealed films are polycrystalline with a $c$-axes preferred orientation. They are highly transparent with an average transmittance $T>80 \%$ which increases, as the annealing temperature increase. The optical band gap of the as implanted films is $\sim 3.19 \mathrm{eV}$ and widens $(\sim 3.3 \mathrm{eV})$ after annealing at elevated temperatures.

\section{Acknowledgments}

This work has been supported by the Slovak Research and Development Agencies, projects VEGA 1/0459/12, 1/0787/09, APVV projects LPP-0094-09, SK-SRB-0012-09, CENTEM project CZ.1.05/2.1.00/03.0088 funded by the R\&D OP from the ERDF of the MEYS CR and by the European Community as an Integrating Activity 'Support of Public and Industrial Research Using Ion Beam Technology (SPIRIT)' under EC contract no. 227012. 


\section{References}

1. D. C. Look, Mater. Sci. Eng., B80, 383 (2001).

2. R. L. Hoffman, B. J. Norris and J. F. Wager, , Appl. Phys. Lett., 82 (5), 733 (2003).

3. H. Liu, V. Avrutin, N. Izyumskaya, Ü. Özgür and H. Morkoç, Superlattices and Microstructures, 48, 458 (2010).

4. S-H. K. Park, J-I. Lee, C-S. Hwang and H. Y. Chuj, Japanese J. Appl. Phys., 44 (7), L 242 (2005).

5. M. Schmidt, M. Ellguth, F. Schmidt, T. Luder, H. v. Wenckstern, R. Pickenhain, M. Grundmann, G. Brauer, and W. Skorupa, Phys. Status Solidi, B 247 (5), 1220 (2010).

6. A. N. Georgobiani, A. N. Gruzintsev, V. T. Volkov, M. O. Vorobiev, V. I. Demin and V. A. Dravin, Nuclear Instr. and Methods in Phys. Research, A 514, 117 (2003).

7. Ch-Ch. Lin, S-Y. Chen, S-Y Cheng and H-Y. Lee, Appl. Phys. Lett., 84 (24), 5040 (2004).

8. Ya. I. Alivov, D. C. Look, B. M. Ataev, M. V. Chukichev, V. V. Mamedov, V. I. Zinenko, Yu .A. Agafonov and A. N. Pustovit, Short Communication, Solid-State Electronics, 48, 2343 (2004).

9. K. Shtereva, I. Novotny, V. Tvarozek, P. Sutta, A Vincze and A. Pullmannova, J. Electrochem. Society, 157 (9), H891 (2010).

10. K. Shtereva, S. Flickyngerova, V. Tvarozek, I. Novotny, J. Kovac and A. Vincze, Vacuum, 86, 652 (2012). 
11. K. S. Shtereva, V. Tvarozek, I. Novotny, P. Sutta, A. Vincze, S. Flickyngerova and M. Vojs, IOP Conf. Series: Materials Science and Engineering, 34, 1 (2012) 012008.

12. J. F. Ziegler, J. P. Biersack, and U. Littmark, The Stopping and Range of Ions in Solids, Pergamon, New York (1985).

13. V. Vaithianathan, Sh. Hishita, J. H. Moon and S. S. Kim, Thin Solid Films, 515, 6927 (2007).

14. E. Ch. Lee, Y. S. Kim, Y. G. Jin, K. J. Chang, Phisica B, 912, 308 (2001).

15. M. Milosavljević, D. Peruško, V. Milinović, Z. Stojanović, A. Zalar, J. Kovač, and C. Jeynes, Journal of Physics D: Applied Physics 43 (2010) 065302 (6pp) 
List of figures and table captions

Figure 1. Normalized depth profiles for $40+80 \mathrm{keV} \mathrm{N}$-implanted $\mathrm{ZnO}: \mathrm{Ga}$ films for implant doses of $1 \times 10^{15}$ and $1 \times 10^{16} \mathrm{~cm}^{-2}$, calculated using the SRIM code.

Figure 2. SIMS depth profiles of the negative ${ }^{30} \mathrm{NO}$ complexes for $40+80 \mathrm{keV} \mathrm{N}$-implanted ZnO:Ga films for implant doses of $1 \times 10^{15}$ and $1 \times 10^{16} \mathrm{~cm}^{-2}$, not annealed.

Figure 3. Resistivity versus annealing temperature for $40+80 \mathrm{keV} \mathrm{N}$-implanted $\mathrm{ZnO}: \mathrm{Ga}$ films, deposited on sapphire substrates and annealed in $\mathrm{N}_{2}$ for $10 \mathrm{~s}$. The plots are for implant doses of $1 \times 10^{15} \mathrm{~cm}^{-2}$ and $1 \times 10^{16} \mathrm{~cm}^{-2}$.

Figure 4. Carrier concentration and mobility versus annealing temperature for $40+80 \mathrm{keV}$ $\mathrm{N}$-implanted ZnO:Ga films, deposited on sapphire substrates and annealed in $\mathrm{N}_{2}$ for $10 \mathrm{~s}$. The plots are for implant doses of $1 \times 10^{15} \mathrm{~cm}^{-2}$ and $1 \times 10^{16} \mathrm{~cm}^{-2}$.

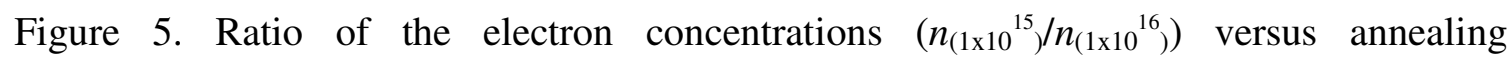
temperature for $40+80 \mathrm{keV} \mathrm{N}$-implanted $\mathrm{ZnO}: \mathrm{Ga}$ films deposited on sapphire substrates and annealed in $\mathrm{N}_{2}$ for $10 \mathrm{~s}$. The inset shows the ratio for the films annealed in $\mathrm{O}_{2}$ for $10 \mathrm{~s}$.

Figure 6. Resistivity, electron concentration and mobility versus annealing temperature for 40+80 keV N-implanted ZnO:Ga films deposited on glass substrates and annealed in $\mathrm{O}_{2}$ for $10 \mathrm{~s}$. The plot is for an implant dose of $1 \times 10^{16} \mathrm{~cm}^{-2}$. 
Figure 7. XRD patterns for $40+80 \mathrm{keV} \mathrm{N}$-implanted $\mathrm{ZnO}: \mathrm{Ga}$ films for implant doses of $1 \times 10^{15}$ and $1 \times 10^{16} \mathrm{~cm}^{-2}$, not annealed.

Figure 8. XRD patterns for $40+80 \mathrm{keV} \mathrm{N}$-implanted $\mathrm{ZnO}$ :Ga films (dose $1 \times 10^{15} \mathrm{~cm}^{-2}$ ). Sample $a$ is not annealed. Sample $b$ and $c$ are annealed in $\mathrm{N}_{2}$ :

b:10 s/400 ${ }^{\circ} \mathrm{C}+10 \mathrm{~s} / 600^{\circ} \mathrm{C}+30 \mathrm{~min} / 600^{\circ} \mathrm{C} \mathrm{c:} 10 \mathrm{~s} / 400^{\circ} \mathrm{C}+10 \mathrm{~s} / 400^{\circ} \mathrm{C}+10 \mathrm{~s} / 400^{\circ} \mathrm{C}$

Figure 9. Optical transmittance spectra for $40+80 \mathrm{keV} \mathrm{N}$-implanted ZnO:Ga films (dose $1 \times 10^{15} \mathrm{~cm}^{-2}$ ), not annealed (black line), and annealed in $\mathrm{O}_{2} / \mathrm{N}_{2}$ at $600^{\circ} \mathrm{C}$ for $10 \mathrm{~s}$. The inset shows the variation of the average transmittance with annealing temperature.

Figure 10. Plot of $(\alpha h v)^{2}$ versus photon energy for $40+80 \mathrm{keV} \mathrm{N}$-implanted ZnO:Ga films(dose $1 \times 10^{15} \mathrm{~cm}^{-2}$ ), not annealed (black line), and annealed in $\mathrm{O}_{2} / \mathrm{N}_{2}$ at $600^{\circ} \mathrm{C}$ for $10 \mathrm{~s}$. 


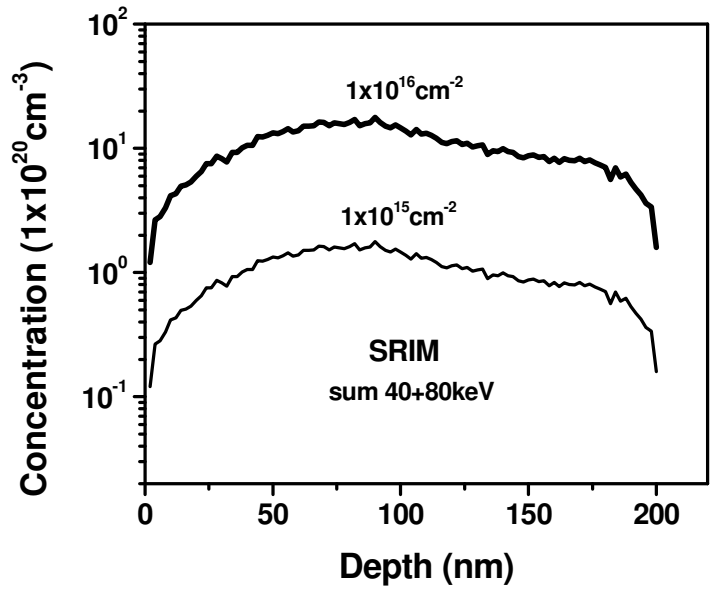

Figure 1. Normalized depth profiles for $40+80 \mathrm{keV} \mathrm{N}$-implanted $\mathrm{ZnO}: \mathrm{Ga}$ films for implant doses of $1 \times 10^{15}$ and $1 \times 10^{16} \mathrm{~cm}^{-2}$, calculated using the SRIM code. 


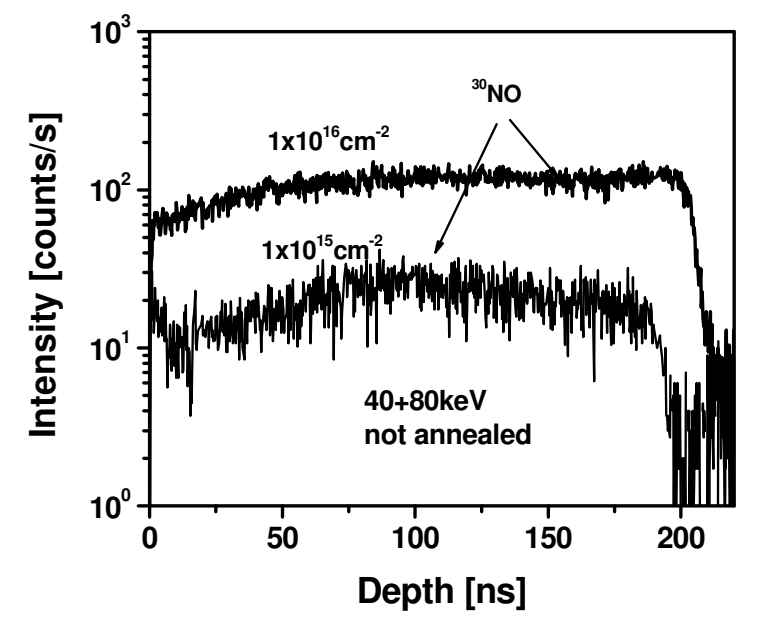

Figure 2. SIMS depth profiles of the negative ${ }^{30} \mathrm{NO}$ complexes for $40+80 \mathrm{keV} \mathrm{N}$-implanted $\mathrm{ZnO}$ :Ga films for implant doses of $1 \times 10^{15}$ and $1 \times 10^{16} \mathrm{~cm}^{-2}$, not annealed. 


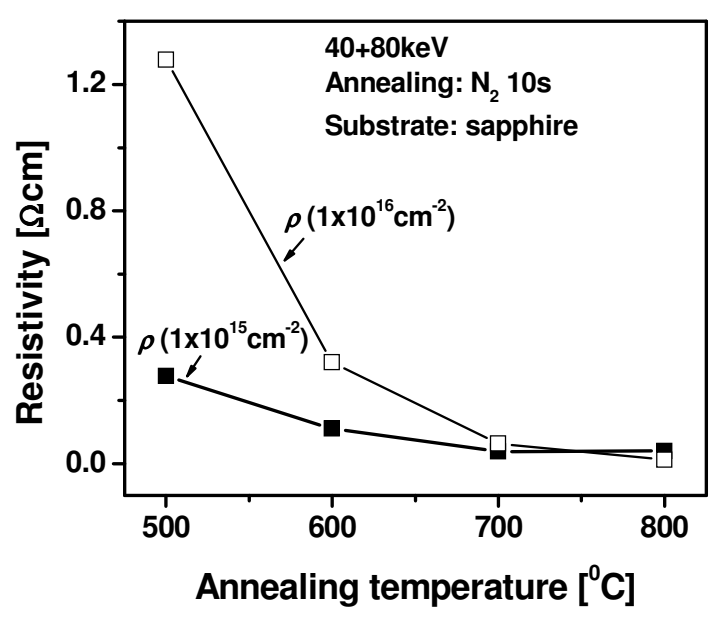

Figure 3. Resistivity versus annealing temperature for $40+80 \mathrm{keV} \mathrm{N}$-implanted $\mathrm{ZnO}: \mathrm{Ga}$ films, deposited on sapphire substrates and annealed in $\mathrm{N}_{2}$ for $10 \mathrm{~s}$. The plots are for implant doses of $1 \times 10^{15} \mathrm{~cm}^{-2}$ and $1 \times 10^{16} \mathrm{~cm}^{-2}$. 


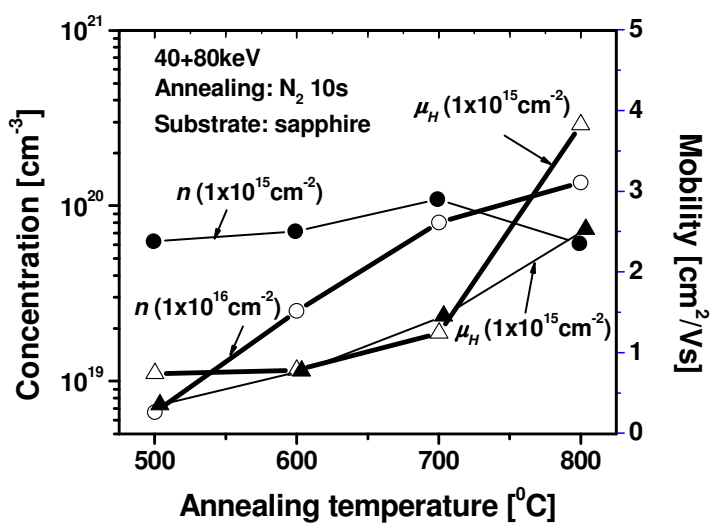

Figure 4. Carrier concentration and mobility versus annealing temperature for $40+80 \mathrm{keV}$ $\mathrm{N}$-implanted ZnO:Ga films, deposited on sapphire substrates and annealed in $\mathrm{N}_{2}$ for $10 \mathrm{~s}$. The plots are for implant doses of $1 \times 10^{15} \mathrm{~cm}^{-2}$ and $1 \times 10^{16} \mathrm{~cm}^{-2}$. 


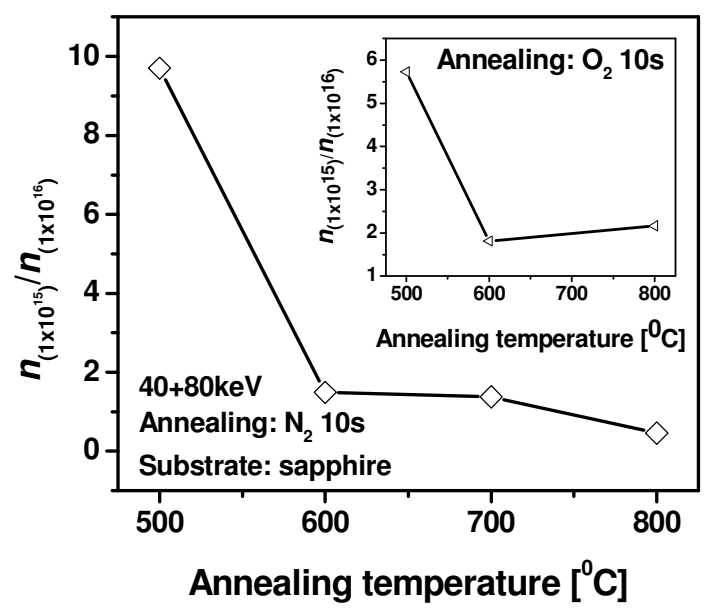

Figure 5. Ratio of the electron concentrations $\left(n_{\left(1 \times 10^{15}\right)} / n_{\left(1 \times 10^{16}\right)}\right)$ versus annealing temperature for $40+80 \mathrm{keV} \mathrm{N}$-implanted $\mathrm{ZnO}: \mathrm{Ga}$ films deposited on sapphire substrates and annealed in $\mathrm{N}_{2}$ for $10 \mathrm{~s}$. The inset shows the ratio for the films annealed in $\mathrm{O}_{2}$ for $10 \mathrm{~s}$. 


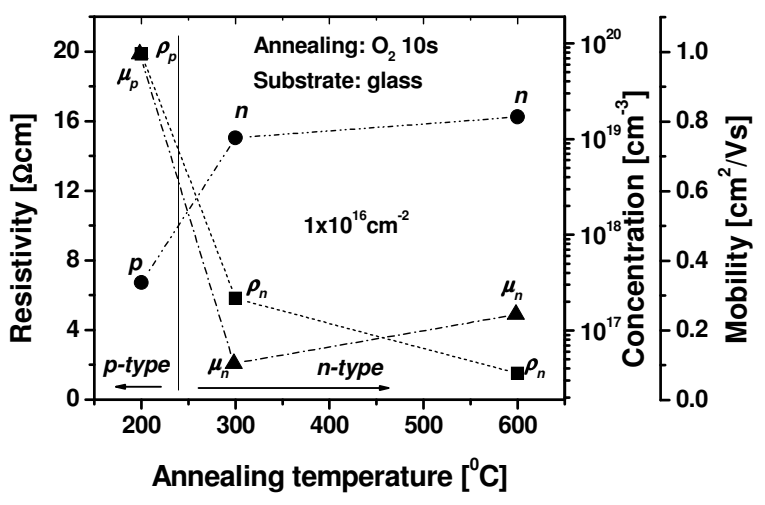

Figure 6. Resistivity, electron concentration and mobility versus annealing temperature for 40+80 keV N-implanted ZnO:Ga films deposited on glass substrates and annealed in $\mathrm{O}_{2}$ for $10 \mathrm{~s}$. The plot is for an implant dose of $1 \times 10^{16} \mathrm{~cm}^{-2}$. 


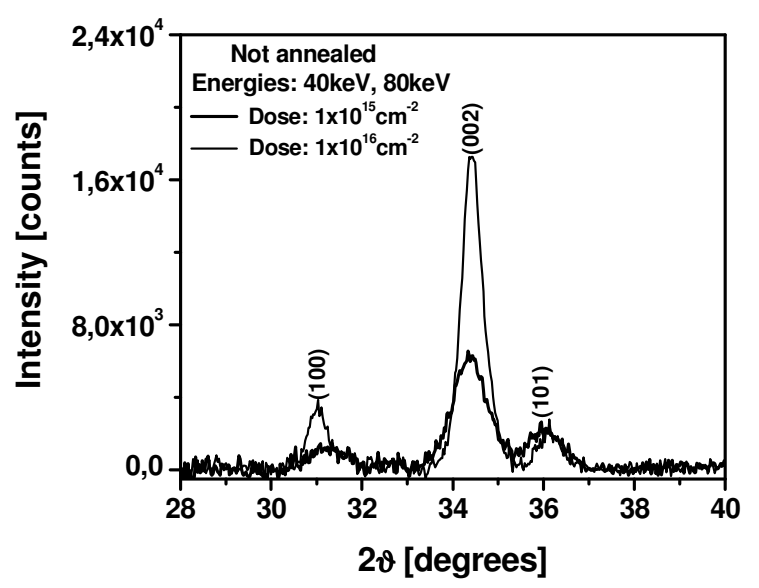

Figure 7. XRD patterns for $40+80 \mathrm{keV} \mathrm{N}$-implanted $\mathrm{ZnO}$ :Ga films for implant doses of $1 \times 10^{15}$ and $1 \times 10^{16} \mathrm{~cm}^{-2}$, not annealed. 


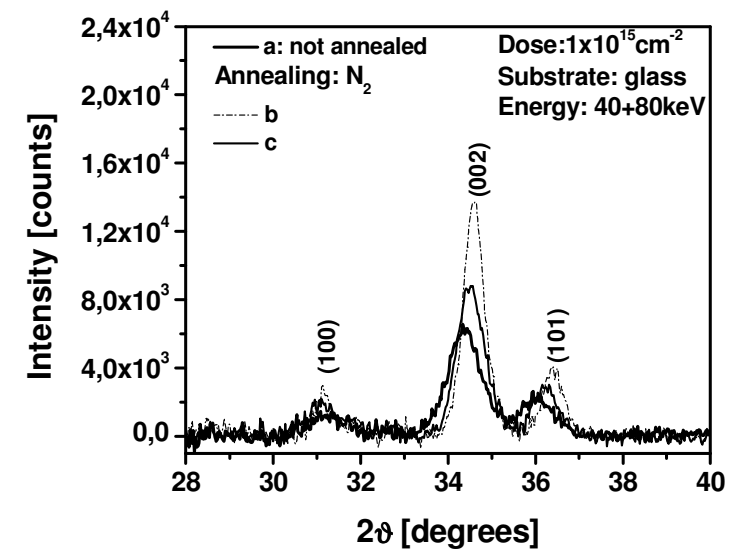

Figure 8. XRD patterns for $40+80 \mathrm{keV}$ N-implanted ZnO:Ga films (dose $1 \times 10^{15} \mathrm{~cm}^{-2}$ ).

Sample $a$ is not annealed. Sample $b$ and $c$ are annealed in $\mathrm{N}_{2}$ :

b: $10 \mathrm{~s} / 400^{\circ} \mathrm{C}+10 \mathrm{~s} / 600^{\circ} \mathrm{C}+30 \mathrm{~min} / 600^{\circ} \mathrm{C} ;$ c: $10 \mathrm{~s} / 400^{\circ} \mathrm{C}+10 \mathrm{~s} / 400^{\circ} \mathrm{C}+10 \mathrm{~s} / 400^{\circ} \mathrm{C}$ 


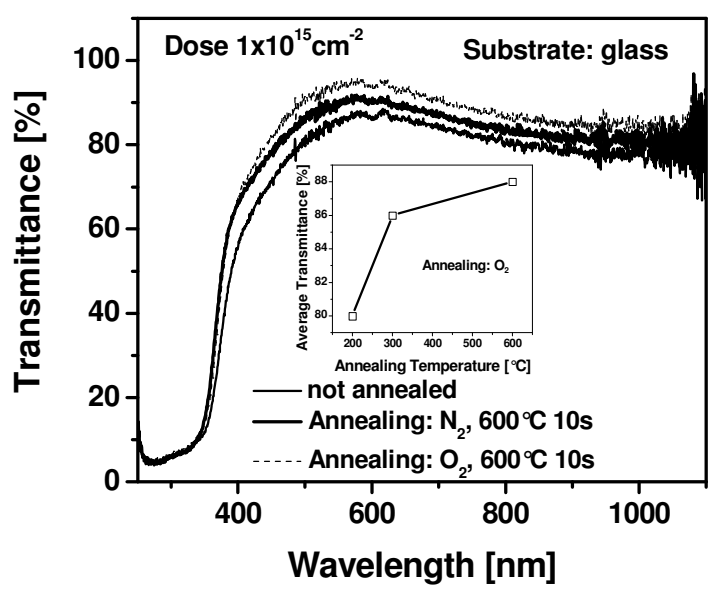

Figure 9. Optical transmittance spectra for $40+80 \mathrm{keV}$ N-implanted $\mathrm{ZnO}$ :Ga films (dose $1 \times 10^{15} \mathrm{~cm}^{-2}$ ), not annealed (black line), and annealed in $\mathrm{O}_{2} / \mathrm{N}_{2}$ at $600^{\circ} \mathrm{C}$ for $10 \mathrm{~s}$. The inset shows the variation of the average transmittance with annealing temperature. 


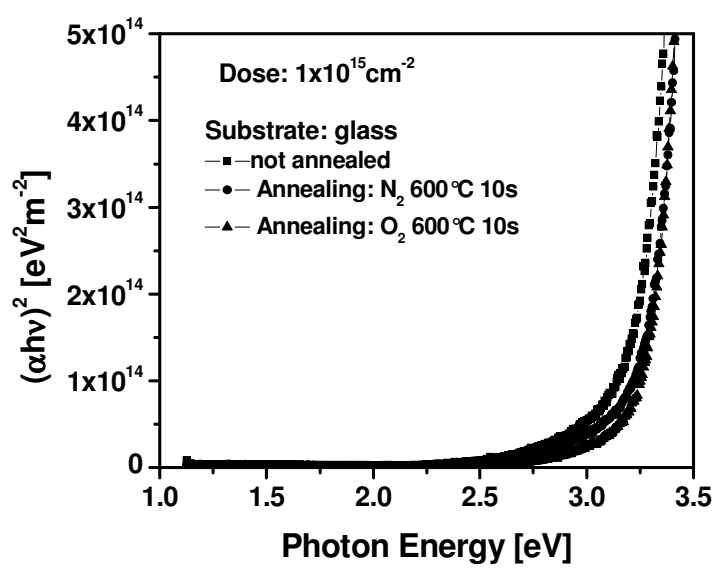

Figure 10. Plot of $(\alpha \mathrm{hv})^{2}$ versus photon energy for $40+80 \mathrm{keV} \mathrm{N}$-implanted ZnO:Ga films (dose $1 \times 10^{15} \mathrm{~cm}^{-2}$ ), not annealed (black line), and annealed in $\mathrm{O}_{2} / \mathrm{N}_{2}$ at $600^{\circ} \mathrm{C}$ for $10 \mathrm{~s}$. 